\title{
This Log: A Poem
}

\author{
Shelley Brandon and Anne Marie Coughlin
}

Shelley Brandon is a toddler educator at Maitland Early Learning Centre with London Bridge Child Care Services. Her strong commitment and passion for supporting children's relationship with the earth has motivated her to create a toddler curriculum that is primarily focused on the outdoors.

Anne Marie Coughlin is the professional development coordinator and program director at London Bridge Child Care Services in London, Ontario, Canada. She currently serves as a Director on the Ontario Reggio Association Board and is Provincial Director for the Canadian Association of Young Children

At London Bridge Child Care Services we share in the belief that growing children deserve growing adults. One of our core professional development practices is to do for educators what we want them to do for children. In other words, if we want educators to foster curiosity and support deep thinking in children, we need to foster curiosity and support deep thinking with them.

One of the ways we do this is to support teacher research through our Master Educator Program. After two years, London Bridge educators are eligible to apply for the 18-month program, where they are supported by mentors in a yearlong research project on a topic they are curious about.

Shelley Brandon, a recent graduate of the program, chose to do her research around the question "How can I support a toddler curriculum in a patch of grass?" Shelley's research stemmed from her deep connection to the outdoors and her strong desire to offer young children meaningful experiences in a natural environment. Her idea was to study how toddlers engaged in an outdoor space that housed nothing but grass, stones, logs, leaves and other items that would naturally be found there.

Among other things, Shelley's research deepened her appreciation for an old log bench that had been a quiet, forgotten part of the playground for years. Over the course of her research, her thinking was transformed as she watched this driedup piece of wood come alive under the careful study of several two-year-olds.

The following is a poem Shelley wrote in response to the wisdom of those children.

\section{This Log}

This $\log$ used to be a tree. Perhaps it was one of many trees on a ridge, or perhaps it stood alone against the horizon - one will never know for sure. We know from its rings that its life spanned several years but we will never know the details of its existence. Who did it shelter from the elements? Who did it nourish? Who did it protect? Who did it inspire?

This log used to be a tree. Somehow at some time it was removed from its original home and altered from its original state. Now it takes form as a miniature bench and has assumed the position as part of our playground landscape. It blends well in its new setting, its potential unnoticed and unsolicited. It is just a log, after all. This log used to be a tree. Through the changes in the seasons, the log remains a constant in our environment. Its weathered exterior is a testimonial to our climate - cracks form along its axis in response to extremes of heat and cold; its rugged bark begins to slip off as the log itself expands and contracts. Its surface becomes polished and slippery with the rain. This log no longer has the defenses against the harsh elements that it once did in its life as a tree.

This log used to be a tree. Its base now presses firmly against the ground, inventing habitats for the tiniest of creatures. Tall grass surrounds its perimeter, shielding it from sight at times. Near record snowfall levels hid this $\log$ from our sight. It is easy to forget about this log at times. It is simply a bench, after all - nothing more, nothing less.

This log used to be a tree. Years pass and its unwavering presence in our landscape make it increasingly difficult for us to ignore, so we accept this log as a permanent fixture in our environment. True, it is no longer a tree, but perhaps in time we would see value in its new form. 
This log used to be a tree. We watch and we wait as this seemingly uninspiring log ignites a transformation. In an instant, this log becomes a hub for social networking, as toddlers form and strengthen relationships with their peers. This log becomes a place for children to test theories, explore boundaries, and take risks. This log became a place to exercise an active imagination and a refuge for solitary reflection - a place for rest, a place for quiet contemplation.

\section{This $\log$ is alive...}

This log used to be a tree. Now we see it as so much more. It has established itself as a place where our youngest citizens can challenge themselves - a place where they are free to ask questions and seek answers. It is a base camp for making discoveries about our world and a place we can go to learn about ourselves. This $\log$ used to be a tree, but now it is a prop for climbing, balancing, and jumping. It provides a surface to build on; it is a vessel with the ability to contain even the smallest pebble or sprinkle of sand. It begs to be poked at, climbed, balanced on, hammered, peeked under, squatted upon, jumped over. This log is admired, revered, and appreciated.

This log used to be a tree. We no longer live in its past; rather we marvel in its presence. This log has opened our minds to the significance of the seemingly insignificant. It has forced us to reexamine our methods and it has allowed us the freedom to let go of our inhibitions. This log used to be a tree. Perhaps it was one of many trees on a ridge or perhaps it stood alone against the horizon - one will never know for sure. We are certain however, that this log does not need roots or branches or leaves to hold a special place in our hearts. Its power rests in its possibilities.

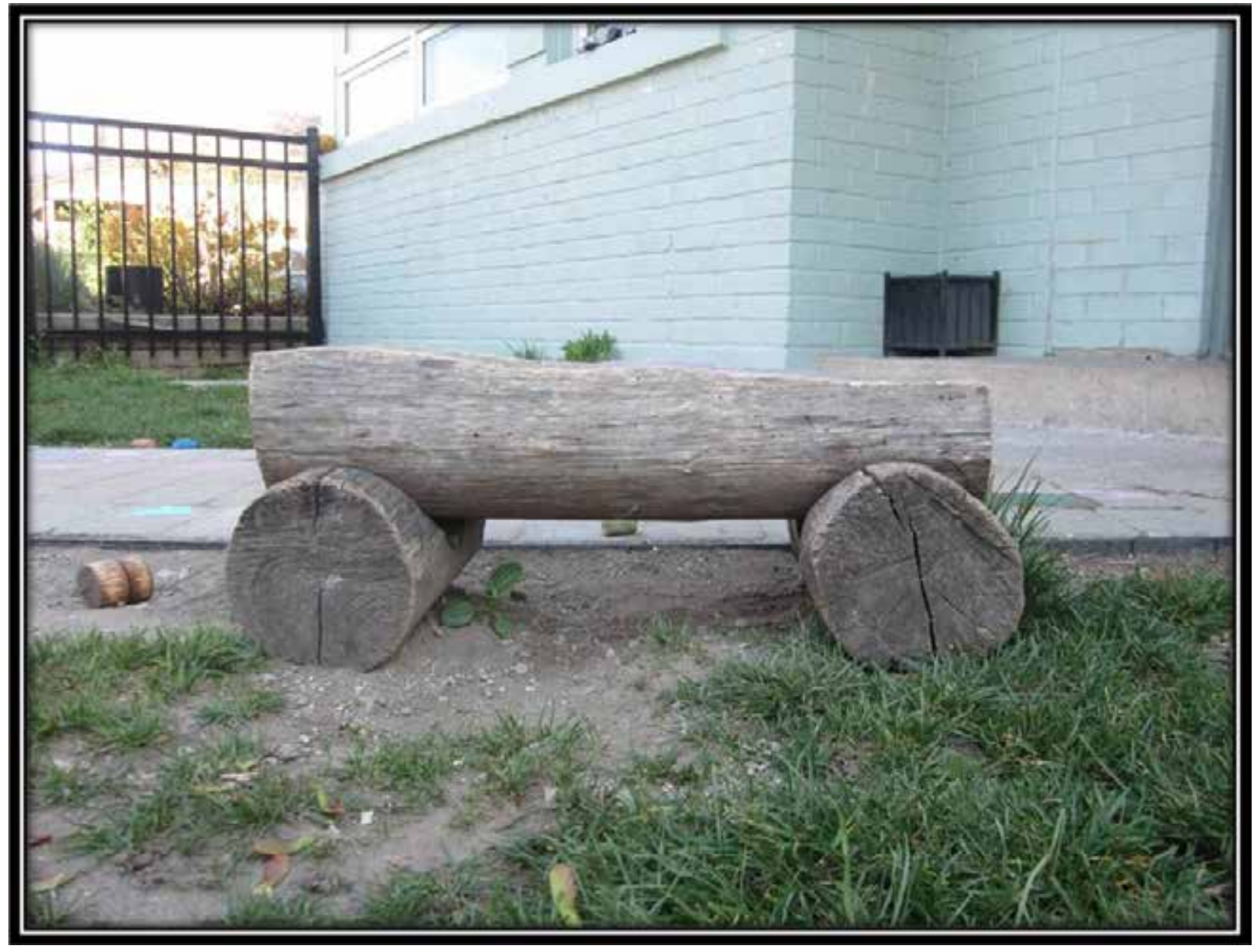

